\title{
PROJETOS DIVERGENTES PARA O CENTRO DE VITÓRIA, ES, BRASIL do ativismo social e do Estado-mercado
}

\section{DIVERGENT PROJECTS FOR VITÓRIA'S CITY CENTER, ES, BRAZIL from social activism to the market-state}

\author{
A. Clara Luiza Miranda \& B. Martha Campos \\ Programa de Pós- Graduação em Arquitetura e Urbanismo, Universidade Federal do Espírito \\ Santo, Brasil \\ claravix@hotmail.com \\ marthamcampos@hotmail.com \\ C. Vinícius Lamego de Paula \\ NUDAM- DPES, Núcleo de Defesa Agrária e Moradia (NUDAM), da Defensoria Pública \\ Estadual, Vitória, Brasil \\ viniciuslamego@hotmail.com
}

\begin{abstract}
RESUMO
A vacância de imóveis no Centro principal de Vitória, ES é contextualizada em face à reestruturação espacial na Região Metropolitana da Grande Vitória. Ao cotejá-la com o crescimento do déficit habitacional e com a necessidade de políticas públicas habitacionais, identificamos uma janela de oportunidade de reuso desses imóveis. Designamos as tentativas e os limites para a reversão do quadro de abandono, efetuadas por meio do planejamento urbano. Ademais, apontamos a inércia do Estado-mercado na implementação de políticas urbanas. No que diz respeito às disputas por espaço no Centro de Vitória, mostramos o advento de uma coalizão conflituosa do ativismo social com o Estado-mercado, a mobilização do direito, especialmente, o direito à cidade. Indicamos também os processos, repertórios e performances transgressivos da coalizão de confronto, alguns efeitos cognitivos, que resultam em conscientização sobre os direitos, além de alguns avanços concretos.
\end{abstract}

Palavras-chave: mobilização do direito; centro urbano; déficit habitacional; Vitória, ES.

Linha de Investigação: 3: Dinâmicas Urbanas Urbanismo insurgente e coletivos urbanos

\section{ABSTRACT}

The vacancy of properties in the main city center of Vitória, ES, is contextualized in view of the spatial restructuring in the Greater Vitória Metropolitan Region. By comparing it to the growth of the housing deficit and the need for public housing policies, we identified a window of opportunity for the reuse of those properties. We designated the attempts and limits for reversing the abandonment situation, made through urban planning. Also, we point out the inertia of the market-state in the implementation of urban policies. Regarding the disputes over space in the city center of Vitória, we show the advent of a conflicting coalition of 


\section{SÃOPAULO15 17 LISBOA $25 \sim 26$ JUN 2020}

social activism against the market-state, the mobilization of rights, especially the right to the city. We also indicate the processes, repertoires and transgressive performances of the confrontation coalition, some cognitive effects, which result in awareness of rights and even in some concrete advances.

Keywords: mobilization of rights; urban center; housing deficit; Vitória, ES.

Research line: 3: Urban Dynamics Insurgent urbanism and urban collectives

\section{Da Hegemonia às desvantagens locacionais: uma introdução}

Vitória, cujo núcleo fundacional data de 1551, adquiriu status de cidade capital na Primeira República, quando se tornou o centro do poder estadual. A hegemonia do Centro principal de Vitória - sítio histórico mais remoto da capital capixaba - perdurou até a década de 1970, quando foi iniciado o processo de deslocamento do interesse imobiliário para outras áreas da cidade e municípios vizinhos. Na década seguinte, foram planejadas e desenvolvidas novas centralidades e, desde então, acentuada a perda de população do centro antigo, comércio e órgãos públicos, cada vez mais atraídos para a faixa litorânea de Vitória, onde o mercado imobiliário usufrui da alta concentração de investimentos públicos.

Em 1990, o intenso crescimento urbano resultou da imigração, causada pela desestruturação da produção rural e da mudança da matriz econômica agroexportadora para industrial-exportadora, que plasmou o espaço físico da Região Metropolitana da Grande Vitória: RMGV1. Então, ocorreu a difusão das novas centralidades e a emergência de subcentros regionais. Fora do Centro principal, surgiu a clusterização de setores de negócios, de comércio, de serviços e da logística, bem como a consolidação de atividades centrais nos principais corredores de circulação da RMGV (IJSN, 2018).

Apesar desses fatores, o Centro ainda detém parte de sua estrutura urbanística e arquitetônica secular, além de redes de infraestrutura urbana, de comércio e serviços, de transporte coletivo, espaços públicos de lazer e cultura, citando-se alguns. Observações in loco e o exame de documentos relativos à área indicam que o uso popular resiste no cotidiano do Centro. Ocupantes de edificações abandonadas, ambulantes, camelôs, trabalhadores e grupos de coletivos de arte e cultura persistem no lugar, mantendo-o como uma centralidade, popular.

Conforme Neil Smith, a expansão do capital conduz a uma dialética da centralização e descentralização espacial, que decorre numa reestruturação do espaço urbano (Smith, 2006: 23). Onde há a diminuição das "economias de aglomeração"; essas são, parcialmente, "substituídas por economias (organizacionais) de escala", configurando imensos "nós de atividade" que estruturam a paisagem urbana (Walker apud Smith, 2006). Tal fenômeno é compatível com o que observamos na RMGV, onde se entrelaçam espaços da produção de escala e de reprodução da população.

Incidem no processo da expansão imobiliária na RMGV: limites decorrentes da propriedade da terra, a autonomia das decisões das elites locais sobre o uso do solo, a descentralização da gestão municipal, induzida pela legislação urbanística pós-Estatuto da Cidade - que estabelece uma aliança local entre Estado e mercado. A expressão disso é que, durante o ápice da crise internacional de 2007 e do reajuste estrutural

\footnotetext{
${ }^{1}$ A RMGV é formada pelos municípios de Cariacica, Fundão, Guarapari, Serra, Viana, Vila Velha e Vitória. Possui extensão de $2.331 \mathrm{~km} 2$, cerca de $5 \%$ da área total do território estadual, abriga estimados 1.687 .704 habitantes, cerca de $48 \%$ da população estadual (IBGE, 2010 apud IJSN, 2018: 20). Constitui-se a principal aglomeração urbana e industrial do Espírito Santo, Brasil.
} 


\section{SÃOPAULO15 17 LISBOA $25 \sim 26$ JUN 2020

nacional (2009-2015), ocorreu, na região, um fluxo financeiro inédito com o Programa Minha Casa Minha Vida, o Programa de Aceleração de Crescimento, a circulação de capitais de empresas de escala nacional atuando no mercado metropolitano. Nesse período, houve crescimento urbano formal simultâneo em zonas diversas da RMGV: áreas periurbanas, periferia, ZEIS, interstícios dos bairros centrais. O centro principal ficou fora da "fronteira econômica" (conceito de Smith, 2007) forjada nesse processo, perdendo vantagens competitivas. Não obstante o crescimento do tecido urbano formal, também se ampliaram os assentamentos autoconstruídos precários, o déficit habitacional e a destruição do meio ambiente. Nesse período, ocupações irregulares de moradia mantiveram-se nas bordas dos bairros periféricos.

O revesso da inércia do Estado-mercado em intervir na área central, que abordaremos a seguir, diz respeito às disputas por espaço no Centro de Vitória e ao advento de uma coalizão conflituosa do ativismo social. São ações insurgentes contra o Estado-mercado, pautadas pela mobilização de direitos, especialmente, o direito à moradia e à cidade. No bojo desse embate, se constituem processos, repertórios e performances transgressivos da coalizão de confronto, que resultam, sobretudo, em conscientização sobre esses direitos, evidenciando a ineficácia do planejamento e da legislação urbanos quando não são implementadas.

\section{As áreas centrais depreciadas e o Estado-mercado}

O capital imobiliário atua constantemente na "simultânea - assim como subsequente" - valorização, decadência, desvalorização, revalorização dos diversos setores da cidade, processo denominado rent gap por Smith. A priori, o rebaixamento dos preços dos imóveis nos centros decadentes atrai a aquisição especulativa, porém o mercado se apresenta para intervir nesses centros, somente, quando as externalidades são positivas, possibilitando obter retorno econômico robusto (Cotelo e Moitay, 2008).

Sales de Oliveira (2017) analisa se as teorias e hipóteses do rent gap são aplicáveis na América Latina e no Brasil. Sua investigação lista as características das áreas centrais propícias ao gap entre a renda capitalizada atual e a renda potencial futura elevada: a boa infraestrutura básica disponível, a localização central e estratégica, o acesso fácil às vias de transporte, a disponibilidade de prédios em desuso; o simbolismo da área, a paisagem e a vida cultural. Segundo ela, essas características configuram "um espaço especialmente atrativo para projetos de renovação urbana" (grandes Operações Consorciadas e Parcerias PúblicoPrivadas). Contudo, o empreendimento, para tornar-se factível, requer um gap elevado (diferença) entre as duas rendas.

Sales de Oliveira (citando Betancur) assinala que a baixa capacidade de autopromoção do mercado afeta a plausibilidade do fenômeno rent gap em países "subdesenvolvidos". A ausência de setores de altos serviços que geram altos salários, o crescente desemprego e a informalidade limitaram a efetivação do rent gap nesses centros: "[...] esses fatores diminuíam a atratividade e o potencial de reuso para áreas centrais, ao passo que exigiam grandes infusões de capitais e ações público-privadas para mudar a situação [...]", diversamente das cidades estadunidenses e europeias (Betancur apud Sales de Oliveira, 2017). Isso converge com as nossas análises sobre o Centro de Vitória.

De fato, nos estudos de Smith (2002) a estratégia do rent gap é utilizada pela elite internacional global em busca de acumulação de capital, agenciando o intercâmbio de investimentos em diferentes setores da cidade. A descontinuidade dos projetos e alianças Estado-mercado no Brasil talvez afete a concretização do processo completo da gentrificação em áreas centrais. Pois, mesmo diante da maior operação urbanística consorciada do Rio de Janeiro e do Brasil, o chamado "Porto Maravilha", que promove violentas remoções e 


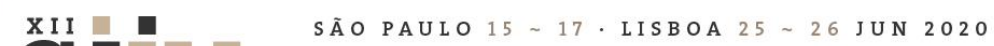

violações de direitos, a valorização espacial e socioeconômica generalizada não se concretiza (Gonçalves, 2020). Ainda, registram-se casos de valorização de setores urbanos depreciados mediante a conversão radical de sua estrutura física, com consecutiva transformação do regime de propriedade e posse por grupos de rendas mais altas. Constituem-se o revés do processo de rent gap, como fenômeno de descentralização. Por exemplo, o setor de torres de negócios das Avenidas Faria Lima e Luís Carlos Berrini, cerca de 9 km do centro principal de São Paulo, projetos de 1995 e 2001, cuja construção promove a expulsão e despossessão dos moradores de classes baixa e média (FIX, 2001). Os dois processos citados baseiam-se em urbanismo de "exceção" (VAINER, 2011), apoiados em grandes volumes de investimentos e benefícios por meio de alianças entre Estado e mercado².

Retornando ao nosso objeto, indagamos: é possível usar taticamente esse intervalo prolongado de desinteresse direto do mercado na área central em favor da promoção de moradia de interesse social e para estabelecer um centro popular? Vinícius Lamego de Paula (2020), partindo do conceito das "janelas de oportunidade", adverte que a abertura dessas janelas se deve à agência dos atores envolvidos na ação coletiva, às coalizões e interações entre eles estabelecidas, à inserção das áreas centrais como território de disputas, à inclusão da segregação socioespacial como enquadramento de injustiça, à conscientização sobre 0 direito à cidade.

\section{3. "Não faltam planos, não faltam leis"}

Políticas públicas de habitação de interesse social ganharam relevância institucional na primeira metade dos anos 1980, com a aprovação do primeiro Plano Diretor Urbano (PDU). Na mesma época, tal como dito, o Centro perde investimentos privados e públicos, se transforma num corredor de passagem, fortalecendo a imagem de deterioração do seu espaço, visto, desde então, como inseguro, poluído, congestionado pelo trânsito intenso, marginal, violento, entre outros atributos negativos.

Registramos planos setoriais que visavam à reversão da situação de degradação ambiental no centro. No plano Vitória do Futuro, de 2002, o diagnóstico foi de "esvaziamento econômico" da área central, como "um processo aparentemente irreversível" (Herkenhoff et alia, 2002). À época tal sentença não procedia, pois havia uma inequívoca vitalidade produtiva e popular no lugar. Além disso, a arrecadação do Centro foi (é) bastante importante. De qualquer modo, entre 1997 e 2004, o Projeto de Revitalização do Centro foi "[...] alçado à projeto prioritário de Governo, prevendo ações estruturais e integradas, no sentido de sua valorização cultural, artística e turística." (Herkenhoff et alia, 2002). Em seguida, o município realizou o Planejamento Urbano Interativo do Centro, um plano setorial que visava a formular ações voltadas para o fortalecimento da identidade, revitalização ambiental e econômica do Centro, entre 2005 e 2006. Em destaque, designam-se as ações municipais de valorização turística e cultural e o programa "Morar no Centro". Contudo, em 18 anos de existência, o programa concluiu apenas três prédios, 94 unidades (VITÓRIA... Acesso em: 01 de jun. 2018). Esses planos não foram capazes de reverter a estagnação da área central, nem a escassez de investimentos tanto por parte da iniciativa privada como do poder público.

\footnotetext{
${ }^{2}$ No caso de São Paulo, Mariana Fix (2001) relata que os instrumentos das operações urbanas são financeirizados mediante os CEPAC: Certificados de Potencial Construtivo Adicional, emitidos pela prefeitura e comercializados pela bolsa de valores. O que decorre na associação entre rentabilidade e valorização dos espaços urbanos garantida pelo ente público.

${ }^{3}$ Frase atribuída à Ermínia Maricato.
} 


\section{SÃOPAULO15 17 LISBOA $25 \sim 26$ JUN 2020

No Plano Diretor Urbano - PDU (Lei o 290 2017) - o centro de Vitória é definido como Macrozona de Reestruturação e designado: Zona Especial de Interesse Urbanístico (ZEIU 1), uma das áreas passíveis de passar por operação urbana consorciada; não há notícia de interessados. O PDU contém inclusive uma detalhada "Política de Proteção ao Patrimônio Histórico, Cultural e Paisagístico do Município". Os espaços construídos e marcos naturais do Centro ostentam historicidade, representatividade e valor cultural indubitáveis para serem contemplados por essa política. Contudo, são poucas as ações e políticas públicas norteadas pelo interesse na proteção dos referentes paisagísticos da área, exceto pelo Plano de Proteção da Paisagem da Área Central de Vitória, concluído em 2011, cuja normativa passa a ter vigência somente no recém-aprovado PDU, em $2018^{4}$. Realce que a ZEIU 1 está indicada para a aplicação do parcelamento, edificação e utilização compulsórias - PEUC ${ }^{5}$. No PDU de Vitória, os instrumentos de política urbana são autoaplicáveis, no entanto, não estão estabelecidas as alíquotas para a cobrança do IPTU Progressivo em imóveis abandonados. Constatamos a ausência de vontade política da autoridade em desempenhar seu papel de instar aos proprietários o cumprimento da função social da propriedade, prevista na Constituição Federal de 1988, no Estatuto da Cidade (2001) e no texto do próprio PDU.

As propriedades em áreas centrais incorporam grande quantidade de recursos sociais e públicos acumulados historicamente. Por isso, os gestores e os beneficiários (os proprietários) destes recursos têm grande responsabilidade. Daí um fator importante da aplicação do PEUC é o de redistribuição dos recursos no espaço urbano, também visando a atender a objetivos fiscais e arrecadatórios, com isso podendo incrementar o fundo municipal de Habitação de Interesse Social - HIS - do município.

\section{A mobilização pelo direito à cidade, marco introdutório}

Neste tópico, delineia-se a problematização das estratégias e táticas utilizadas pelas duas principais coalizões que disputam politicamente o Centro: a do Estado-mercado e a de confronto, formada pelos ativistas pelo direito à cidade. Isso envolve a mobilização do direito, abordada mediante o destaque dos repertórios designados por Vinícius Lamego de Paula (2020), dentre os quais: o ciclo de ocupações de moradia; a atuação judicial; as atividades acadêmicas; a Campanha da Função Social da Propriedade. A Teoria da Mobilização do Direito compreende o direito não de uma forma meramente instrumental, restrita às instituições de justiça, às normas legais e aos agentes de justiça, mas como um processo cultural, que envolve a construção de significados, a partir da interação entre diversos atores, tanto nos espaços institucionais quanto nos ambientes informais. Nos dizeres de McCann (2010): "[...] o enfoque da mobilização do direito [...] desloca o foco dos tribunais para os usuários e utiliza o direito como um recurso de interação política e social (McCann, 2010: 182). Por exemplo, o mesmo autor, mostra como o direito à cidade (Lefebvre, 2006) ${ }^{6}$ passou a ser mobilizado no contexto das ocupações do Centro de Vitória, também na realização de uma campanha com a finalidade de conscientização sobre o Direito à Cidade e ao princípio da Função Social da Propriedade (Paula, 2020).

\footnotetext{
${ }^{4}$ A paisagem como objeto político capaz de mediar e regular socialmente certos territórios encontram referência de política pública renovada no citado Plano, o qual uma das autoras deste artigo - Martha Machado Campos - teve a oportunidade de coordenar.

${ }^{5}$ Esses instrumentos estão previstos na Constituição Federal da República (Brasil, 1988), no Estatuto da Cidade (Brasil, 2001) e nos Planos Diretores dos municípios e consistem no: 1) parcelamento, edificação e utilização compulsórios (PEUC); 2) no Imposto Predial e Territorial Urbano (IPTU) progressivo no tempo; 3) na desapropriação sancionatória com pagamento mediante títulos da dívida pública. ${ }^{6}$ Conforme entendimento de Lefebvre, o direito à cidade excede o direito à propriedade e às coisas que já existem, abarcando o direito de fazer a cidade, a atividade participativa, a apropriação e a autogestão que propiciam o desenvolvimento social.
} 


\section{XII

O direito à cidade, idealizado por Lefebvre (2006), consiste no direito à vida urbana, transformada e renovada, em que o urbano seja um local de encontro, privilegiado como valor de uso e não de troca. Para o autor (Lefebvre, 2006), o direito à cidade não se confunde com o direito de satisfação das necessidades individuais de uma sociedade de consumo, esse deve servir às necessidades antropológicas socialmente fundamentadas. Por sua vez, David Harvey (2012) coloca o direito à cidade como um dos mais importantes e inobservados direitos humanos, trata-se de um direito coletivo que não se confunde no acesso aos recursos humanos, mas se baseia no direito de todos participarem do processo de construção das cidades.

Especificamente em relação à Campanha da Função Social da Propriedade, apresentaremos, sinteticamente, as performances que compõem esse repertório e que contaram com a participação dos seguintes atores : associações de moradores, coletivos urbanos, movimentos sociais de moradia e sociedade civil, em particular, a Associação dos Moradores do Centro - Amacentro, o Br Cidades, o Brigadas Populares, o Movimento Nacional de Luta por Moradia - MNLM, a Defensoria Pública Estadual e a Universidade Federal do Espírito Santo.

\section{Vacância de imóveis e déficit habitacional}

O estudo do Planejamento Urbano Interativo do Centro (Vitória, 2006) constatou a existência de 100 edificações desocupadas e 216 subutilizadas no Centro de Vitória. Verificamos que, 13 anos depois, a situação não se modificou. No ano de 2019, a partir da Campanha da Função Social da Propriedade, acima mencionada, em especial de um canal de denúncias de imóveis desocupados no centro da cidade, aberto em parceria com a Defensoria Pública do Estado do Espírito Santo, foi possível atualizar o mapa, no qual passou a constar o total de 127 imóveis ociosos (Figura 01). Cabe destacar que essa quantidade de imóveis vazios ou subutilizados se concentra em uma pequena área de $2 \mathrm{~km}^{2}$, formando focos de degradação urbana, que geram externalidades negativas, abrangendo as construções da vizinhança.

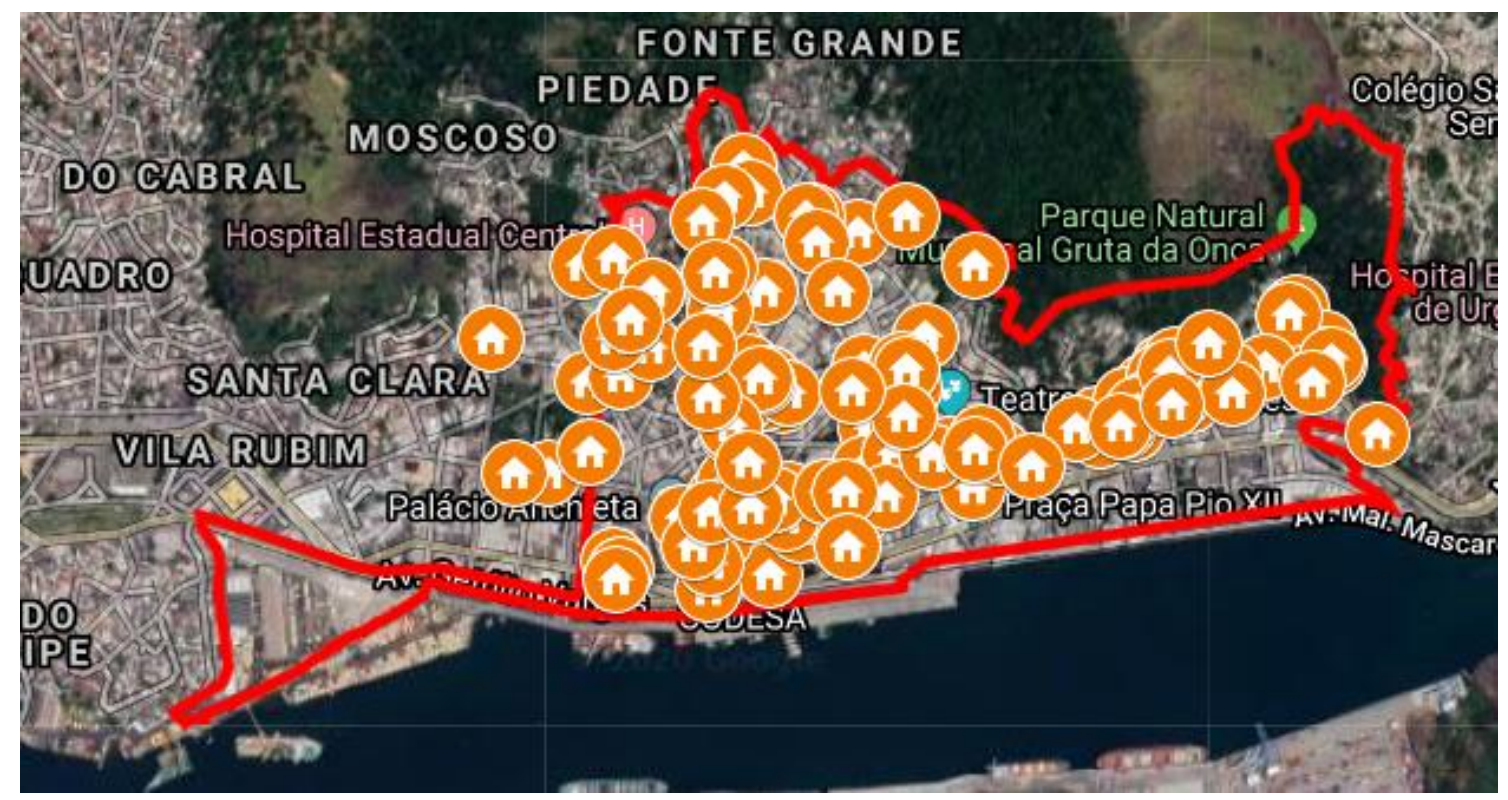

Fig. 01 Mapa de imóveis ociosos no Centro de Vitória. Dados coletados na Campanha da Função Social da Propriedade sobre mapa do Google. Paula, 2020. 


\section{XII $\quad$ SÃOPAULO $15 \sim 17 \cdot$ LISBOA $25 \sim 26$ JUN 2020

O problema do déficit habitacional não se confunde com a insuficiência de unidades habitacionais construídas. As pesquisas da Fundação João Pinheiro demonstram que o número de unidades habitacionais vazias é superior ao déficit habitacional. De acordo com essa Fundação, o déficit habitacional do Estado do Espírito Santo, no ano de 2015, era de 109.535, enquanto existiam 171.518 domicílios vagos em condições de serem ocupados (FJP, 2018).

Do total do déficit habitacional existente no Espírito Santo, o Instituto Jones dos Santos Neves, em estudo referente ao ano de 2016, verificou que 47,66\% se concentravam na Região Metropolitana de Vitória. (IJSN, 2017). O mesmo IJSN, ao analisar os dados do CAD-único (que não retratam o total do déficit habitacional) ${ }^{7}$, constatou, no ano de 2016, um total de 6.215 famílias de baixa renda em situação de déficit habitacional (IJSN, 2017).

Há notícias sobre a ocupação de edifícios vacantes no Centro de Vitória pelo MNLM, na década de 1990, mas o processo estagnou-se por alguns anos. Em São Paulo, por exemplo, elas ocorrem desde 1997, sendo que, em 2018, havia 206 ocupações (Secretaria Habitação PMSP apud G1... Acesso em: 22 de fev. 2020). As ocupações no Centro de São Paulo exercitam o questionamento do modelo hegemônico de urbanização da sociedade brasileira, consistindo na refutação da lógica de periferização da pobreza e numa forma de luta pelo direito à cidade, que serve aqui como parâmetro para a compreensão das ocupações de Vitória (Trindade apud Paula, 2020: 55).

\section{A mobilização pelo direito à cidade, a coalizão de confronto}

Diante desse quadro, pergunta-se: por que os imóveis vazios no Centro de Vitória começam a ser ocupados de forma mais contínua, a partir do ano de 2017? Para dar essa resposta e compreender como esse processo ocorreu, não é suficiente apontar apenas os fatores estruturais relacionados ao abandono do Centro, ao elevado déficit habitacional, ao desemprego e à existência de um elevado número de prédios abandonados. Faz-se essencial analisar os aspectos micros sociais relacionados aos atores e as interações que foram sendo estabelecidas desde a ocupação da "Fazendinha" em janeiro de 2017.

A análise mais detalhada do fenômeno das Ocupações no Centro de Vitória, a partir dos seus elementos menos estruturados se deu na dissertação de mestrado de Vinícius de Paula (2020), a qual se valeu de uma abordagem microssocial e culturalista da ação coletiva, trabalhada por James Jasper (1997). Em sua teoria, Jasper (1997) ressalta a importância da cultura na ação coletiva, o que envolve: os comportamentos mentais de cunho moral, cognitivo e emocional compartilhados e suas representações; os indivíduos, os eventos, o tempo, o espaço e as passagens de vida.

Partindo-se dos atores que compõem a ação coletiva que envolve as Ocupações no Centro de Vitória, Paula (2020), constatou a existência de uma densa rede informal de atores, que se aproxima do que Diani e Bison (2010) classificam como coalizão conflituosa. Essa coalizão é constituída por um diversificado grupo de indivíduos e organizações, que mantêm uma autonomia e independência entre si, e que visam a perseguir um objetivo comum, no caso: a promoção de políticas habitacionais e de desenvolvimento urbano pelo poder público, em especial, neste caso, pelo Município de Vitória. Essa ação é conflituosa, na medida em que a sua

${ }^{7}$ O Estudo, desenvolvido pelo IJSN e publicado no ano de 2016, utiliza como base os dados do CadÙnico de 2015. Uma vez que contabiliza apenas as pessoas inscritas no CadÚnico, o total de pessoas em situação de déficit habitacional não representa o total da população de Vitória nesta situação. Consideram-se em situação de déficit habitacional as famílias com onerosidade excessiva do aluguel (pessoas que recebem até 3 salários mínimos e gastam mais de $30 \% \mathrm{com}$ o aluguel), famílias em coabitação forçada, adensamento populacional excessivo e habitação precária. 


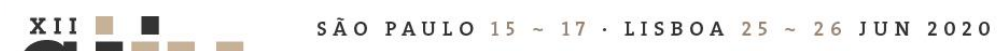

atuação se contrapõe aos interesses da coalizão Estado-mercado, dos proprietários dos imóveis ocupados, tanto os particulares como a União, o Estado do Espírito Santo e o Município de Vitória.

Apesar de não identificar, nessa rede de atores, a existência de uma identidade coletiva fortemente consolidada, por meio da participação conjunta em eventos passados, como em um movimento social, Paula (2020) aponta que a relação mantida entre os atores no caso analisado não é meramente instrumental, se desenvolvendo não apenas a partir de processos racionais, mas também de processos morais e emocionais, podendo ser constatada a existência de uma sensação de pertencimento e de futuro comum entre esses atores.

No caso em questão, Vinícius de Paula (2020) demonstra que a rede de atores de atores vai sendo formada desde a primeira ocupação, ocorrida na área denominada como "Fazendinha", até as ocupações se deslocarem para o centro de Vitória, quando se fortalece. Essa rede é composta pelas pessoas que vivem nas ocupações (os ocupantes), os grupos que atuam na organização das ocupações e de atores que prestam algum tipo de assistência ou apoio aos ocupantes e às ocupações. Além disso, é composta por defensores públicos estaduais do Núcleo de Defesa Agrária e Moradia (NUDAM), da Defensoria Pública de Vitória, pelo Coletivo Resistência Urbana, que surge pela união entre três atores que organizam as ocupações e pelo Núcleo do BrCidades GV, formado principalmente por alguns atores que atuam como apoiadores das ocupações. A rede está representada na figura abaixo:

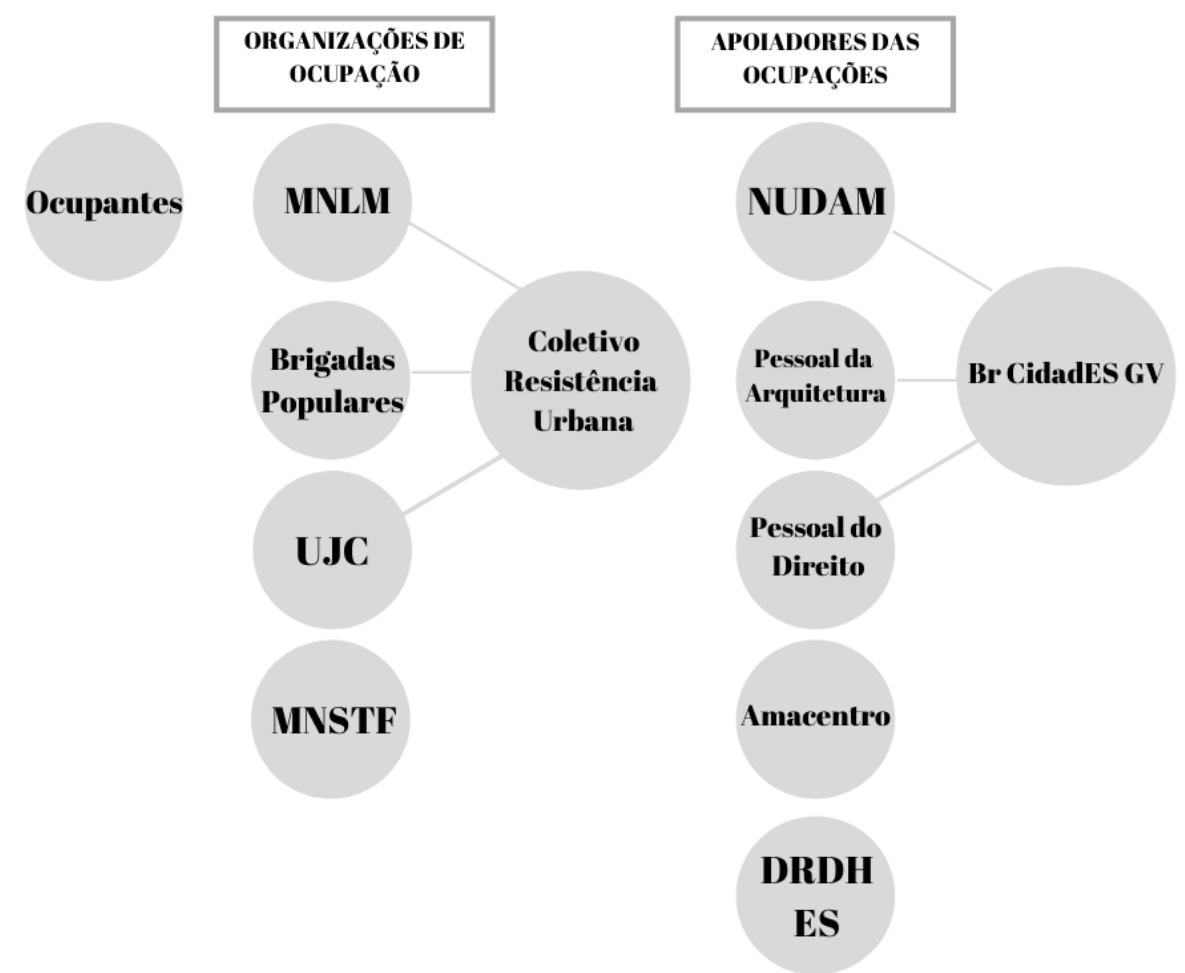

Fig. 02 Atores da rede de mobilização do direito à cidade em Vitória. Paula, 2020. 


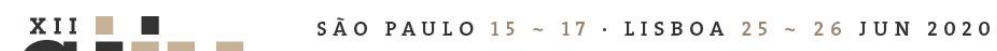

A coalizão conflituosa em análise, envolve o direito de várias formas diferentes, se enquadrando como um processo de mobilização do direito, nos termos trabalhados por Michael McCann (1994, 2010). Com base em Frances Zemans (1983, p. 700, apud McCann, 1994, p.6): o direito é ... mobilizado quando um desejo ou expectativa é trazido em uma demanda como uma asserção de direitos. (tradução nossa). No caso em questão, Paula (2020) identificou que a mobilização do direito se dá através do emprego de 04 repertórios distintos $^{8}$ : as ocupações; a atuação judicial; as atividades acadêmicas; a Campanha da Função Social da Propriedade. Esses repertórios, por sua vez são constituídos por um conjunto de performances que, nos dizeres de Cristiana Losekann (2019, p. 188) consistem nas interações em suas formas empíricas, dinamizadas pelas experiências concretas das pessoas em interação.

O repertório da Campanha da Função Social da Propriedade envolveu todos os atores participantes da rede informal que compõe a coalizão de confronto sintetizada na figura 02. Tendo reunido essa ampla diversidade de atores e devido ao seu caráter criativo e inovador, ela contou com vários tipos de performances, algumas mais típicas das atividades acadêmicas (divulgação de pesquisas e informações), outras mais próprias do ambiente jurídico e da Democracia Participativa (realização de audiências públicas e participação em Sessão Legislativa), outras típicas das organizações sociais (atividades interativas de conscientização, protesto e denúncia dos imóveis vazios no Centro de Vitória, intervenções artísticas e culturais, panfletagem, recolhimento de abaixo-assinados, criação de símbolos). Em seguida, analisamos os principais eventos ocorridos, em acordo com a linha do tempo da Campanha esquematizada na figura 03.

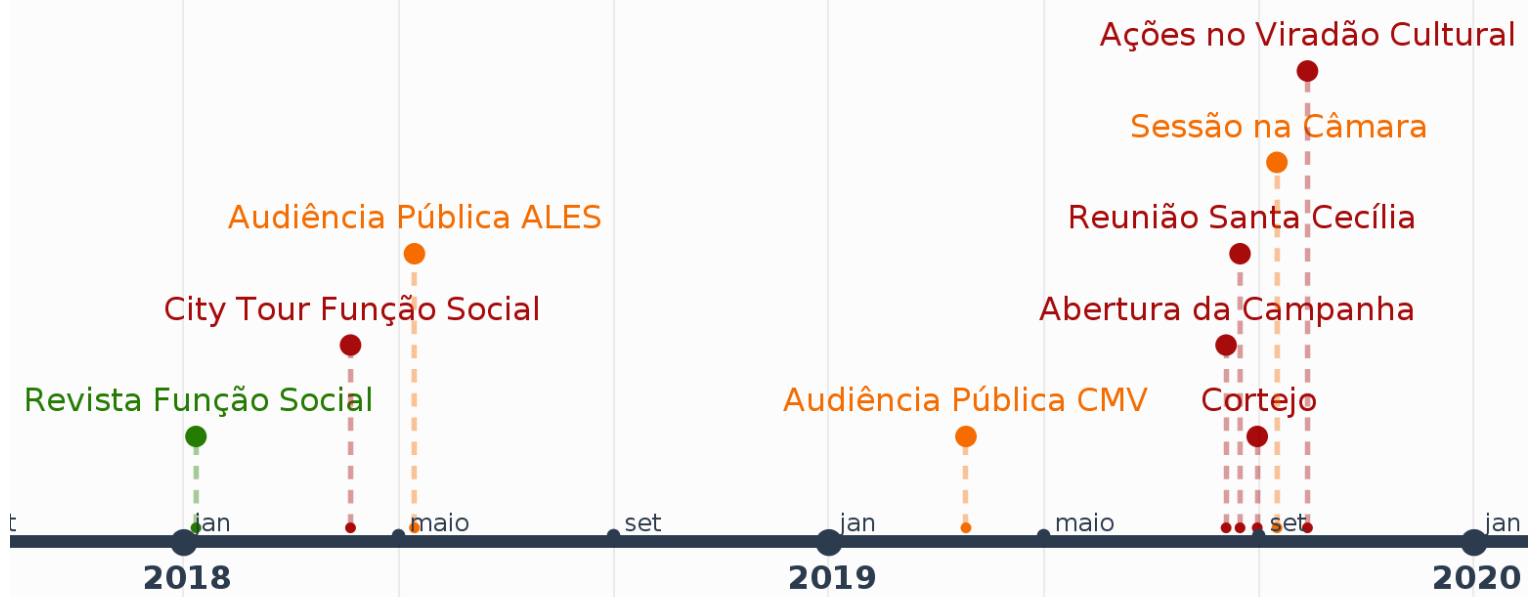

Fig. 03 Linha do tempo da Campanha da Função Social da Propriedade. Locais: Centro, ALES, CMV. Atores: Amacentro, defensores públicos, profissionais e alunos de Arquitetura e Urbanismo e Direito, atores das organizações de ocupação, ocupantes, deputados, vereadores, secretários municipais de habitação. Eventos: Atividades educativas de conscientização e mobilização, audiências públicas, sessão legislativa. Lamego, 2020.

\footnotetext{
${ }^{8}$ O termo repertório é utilizado por Charles Tilly $(1977,2001,2008)$, na sua teoria do confronto político, para tratar das formas da ação coletiva. Ao tratar da evolução desse conceito no pensamento de Tilly, Alonso (2012) aponta que ele passa por três momentos: inicialmente ele possui um caráter estático, admitindo-se a sua variação apenas a partir de fatores históricos; em um segundo momento, ele se torna mais dinâmico, passando a variar também pela agência dos atores; em um terceiro momento, adiciona-se o conceito de performance ao de repertório, dando-se mais espaço para a agência dos atores.
} 


\section{SÃOPAULO15 17 LISBOA $25 \sim 26$ JUN 2020}

O NUDAM já havia aberto um procedimento para diagnosticar a implementação dos instrumentos PEUC de fiscalização da função social da propriedade nos municípios capixabas. Diante das ocupações de imóveis abandonados no Centro e pela relevância que o assunto adquiriu, realizou uma pesquisa sobre a implementação desses instrumentos e a publicou em 2018. O resultado da pesquisa foi apresentado em uma reunião da Comissão de Direitos Humanos da ALES, tendo sido tomado como encaminhamento a realização de uma audiência pública.

Em maio de 2018, foi realizada uma audiência pública na ALES para discutir o déficit habitacional nos municípios da Grande Vitória, contando com a participação de Deputados, Secretários de Habitação dos Municípios de Vitória e Vila Velha, defensores públicos federais e estaduais, representantes das Brigadas Populares, do MNLM, pessoas de diversas ocupações da RMGV, do Movimento Nacional dos Sem Teto em Situação de Rua (MNSTR), Movimento da População em Situação de Rua, de representante da Amacentro, de profissionais de Arquitetura e Urbanismo. Essa audiência pública contribuiu para pressionar os poderes executivos municipais e para divulgação da luta pela moradia no centro.

Em março de 2019, foi realizada nova audiência pública, na Câmara de Vereadores de Vitória, para tratar mais especificamente da questão do direito à moradia na cidade de Vitória. Dela, participaram vereadores, defensores públicos do Estado e da União, atores dos movimentos sociais, ocupantes, representantes da Amacentro, da Ordem dos Advogados do Brasil (OAB), acadêmicos do Direito e de Arquitetura e Urbanismo. O Prefeito do Município de Vitória foi convidado para participar, mas não compareceu nem enviou representante à audiência. $\mathrm{Na}$ ocasião, vários ocupantes demonstraram conscientização dos direitos e empoderamento pela participação nesse processo de mobilização. Ademais, o vereador que a convocou apresentou um Projeto de Lei para a regulamentação do IPTU progressivo (PL 72/2019) e para a destinação do valor arrecadado para o Fundo Municipal de Habitação de Interesse Social (FMHIS).

Em agosto, houve o lançamento da Campanha da Função Social da Propriedade, da qual participam a Amacentro, a DPES, a UFES e o BrCidades, com o intuito de conscientizar a população sobre o conceito da Função Social da Propriedade e de exigir a implementação dos instrumentos para sua fiscalização. Essa campanha visa ao preenchimento de abaixo-assinado e ao recebimento de denúncias de imóveis abandonados pelos moradores e frequentadores do centro. 


\section{SÃOPAULO $15 \sim 17 \cdot$ LISBOA $25 \sim 26$ JUN 2020}

Seminário Internacional de Investigação em Urbanismo

Seminario Internacional de Investigación en Urbanismo

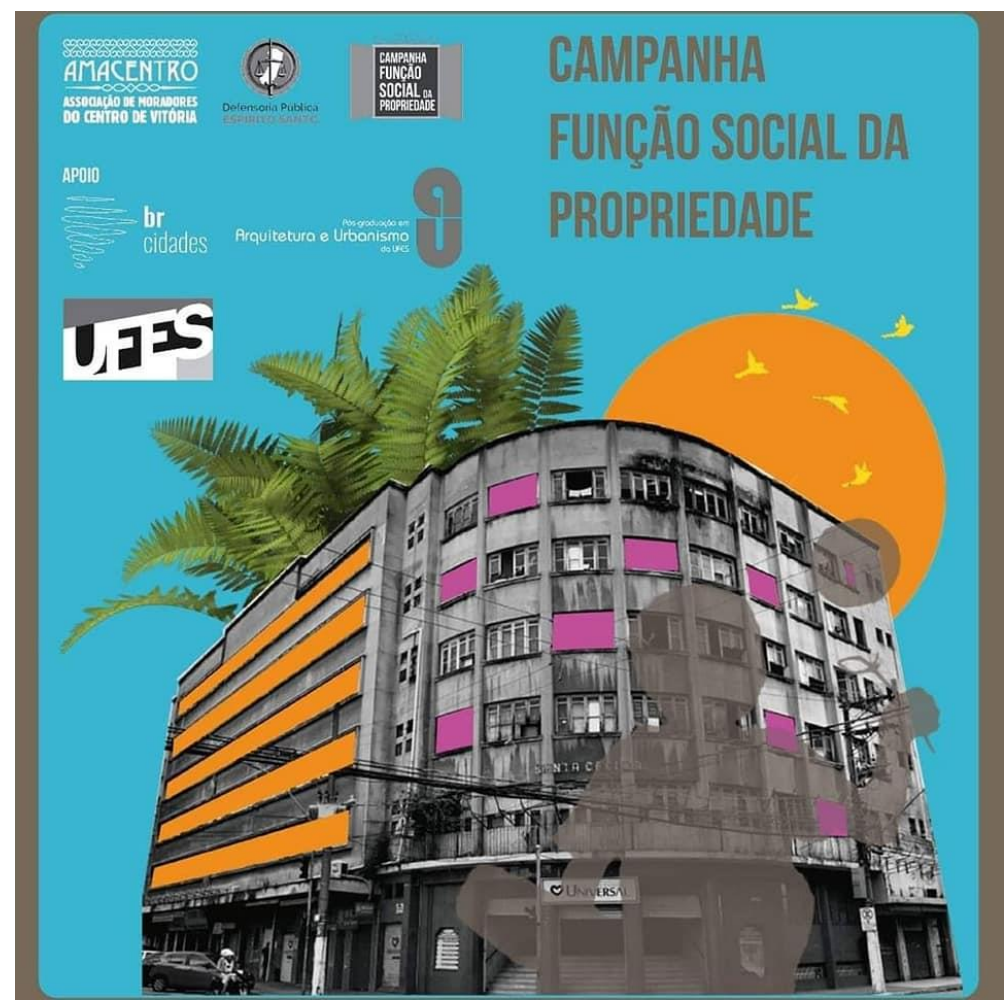

Fig. 04 Material impresso de divulgação da Campanha da Função Social da Propriedade. Fonte: BrCidades ES-GV, 2019. Elaboração de: Mário Margotto, Marina Coelho e Lucas Damm Cuzzuol.

Uma das atividades de conscientização foi a realização de um cortejo, em agosto, pelas ruas do Centro de Vitória, conduzido por artistas, com músicas e instrumentos, passando pelos imóveis abandonados. Esse evento contou com a participação dos moradores das ocupações, de representantes da Amacentro, do MNLM, do BrCidadES GV, das Brigadas Populares, da UJC, de estudantes e profissionais de Arquitetura e Urbanismo e do Direito, de defensores públicos do NUDAM, de um vereador e do público em geral. Essa atividade foi um momento de protesto, mas também de grande celebração entre os atores, como pode ser visto na figura 05. 


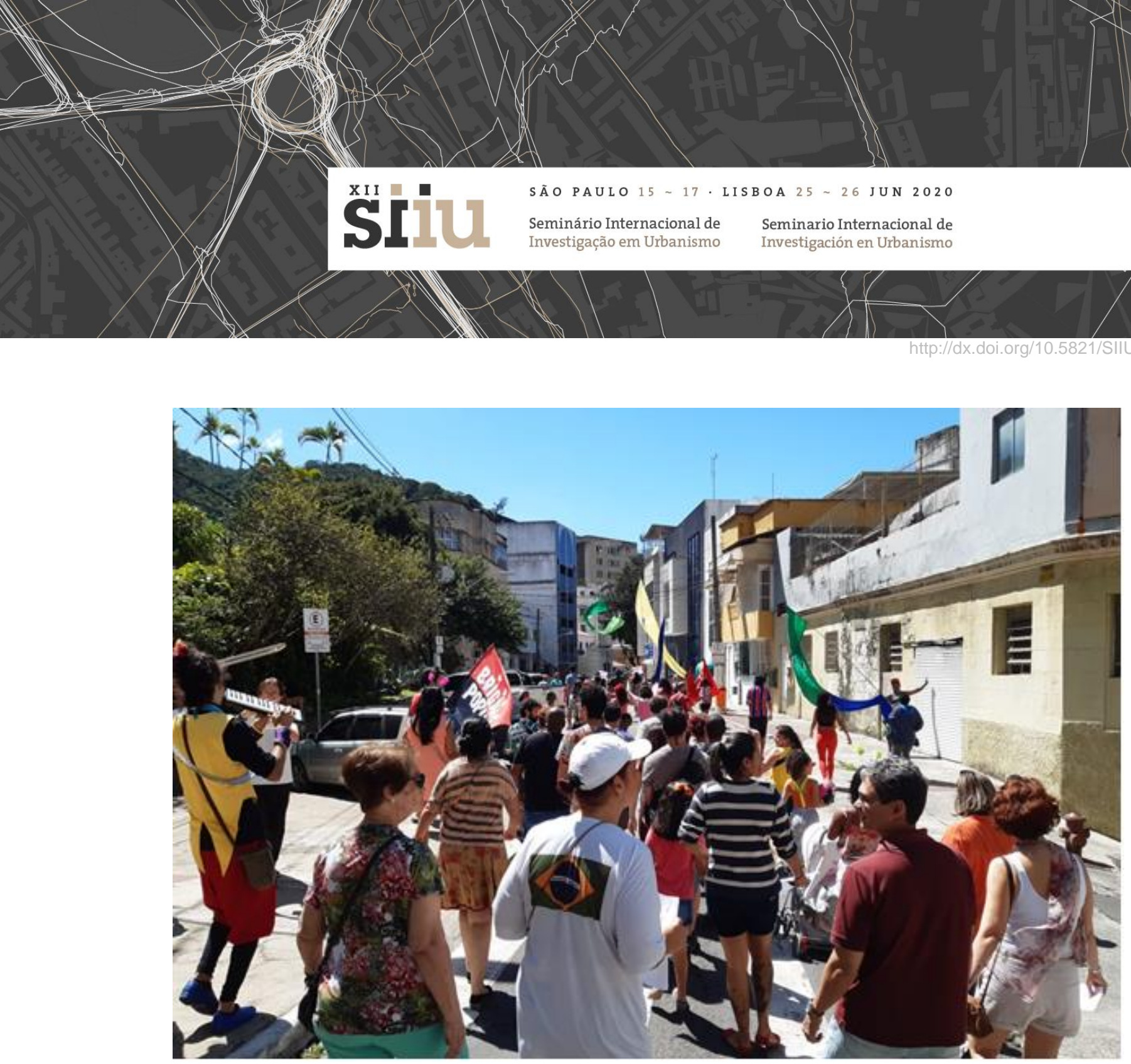

Fig. 05 Cortejo da Campanha da Função Social da Propriedade. Fonte: BrCidades ES-GV, 2019.

Em setembro de 2019, na Sessão da Câmara de Vereadores de Vitória, o Projeto de Lei para a regulamentação do IPTU Progressivo foi colocado em pauta para a votação. Um defensor do NUDAM e uma componente do BrCidadES GV se inscreveram para falar e defender o projeto de lei. Contudo, nas vésperas da votação foram apresentadas duas emendas ao projeto. O NUDAM chegou a apresentar nota técnica contra uma das emendas, mas a votação acabou sendo adiada. Finalmente, a votação foi realizada, em 15 de outubro. A proposta de regulamentação do IPTU Progressivo foi rejeitada por 10 a 2 pelos vereadores.

Essa campanha mostra como a mobilização do direito à cidade, em Vitória, pela interação entre atores tão distintos como agentes de justiça, estudantes, professores, representantes de associações de bairro, organizações envolvidas nas ocupações e ocupantes, resultou em repertórios inovadores, se enquadrando como uma forma de confronto transgressivo (Tilly, McAdam, Tarrow, 2001). Isso corrobora com o argumento de Losekann (2019), de que os confrontos judiciais não são apenas contidos, mas também podem ser transgressivos, resultando na constituição de novos atores, utilizando estratégias não convencionais e promovendo transformações sociais e institucionais.

\section{Conclusão}

O conflito entre as duas coalizões é uma disputa assimétrica: enquanto o Estado-mercado (poder econômico) tergiversa sobre um projeto para o Centro de Vitória, breca e desqualifica os projetos daqueles que desejam produzir e viver ali, assim como criminaliza os movimentos de moradia, a coalização de confronto se esforça 


\section{SÃOPAULO15 17. LISBOA $25 \sim 26$ JUN 2020}

para forjar uma fronteira política numa conjuntura baseada na austeridade e no confisco de salários, bens e serviços públicos.

A agenda para um Centro popular encontra-se somente esboçada, porém se apreende que, para encaminhála, é preciso agenciar a produção da cidade que o mercado formal não abarca: entre $40 \%$ e $50 \%$ da cadeia produtiva da construção civil é informal e cerca de $85 \%$ da população não recorre à assistência técnica (CAU; Data Folha, 2017). O processo requer contestação da lógica do negócio e da austeridade incorporada pela administração pública. Indica que o movimento social deve assumir uma parcela das responsabilidades do Poder Público. O direito à cidade implica exatamente o exercício da atividade participativa na produção e gestão do espaço social.

Quanto às novas experiências e aos novos repertórios, a mobilização por direitos, adquirida desde os movimentos da década de 1980, via atores do MNLM, pode ajudar na elaboração de proposições criativas para mitigação ou superação dos quadros adversos de déficit habitacional e de abandono de imóveis no Centro de Vitória, o que abre uma janela de oportunidade.

Para concluir, da agenda nacional do BrCidades (2020), da qual somos signatários, extraímos algumas indicações que conciliam o problema da moradia popular e da reabilitação das áreas centrais pelas quais a coalizão de conflito pode se guiar.

Em nossas leituras e análises contatamos que, em sua maioria, parcerias público-privadas, operações urbanas consorciadas privilegiam o interesse privado, não cumprindo a função social da cidade. Assim, a previsão desse tipo de intervenção urbana deveria ser excluída da ZEIU1 do Centro de Vitória. Devemos continuar lutando para que os PEUC sejam imediatamente regulamentados, aplicados conforme o PDU de Vitória determina. Para que essa ação seja efetiva, é inevitável reabilitar o Programa Morar no Centro, assim como criar programas dirigidos a novas modalidades de atendimento, como idosos e população em situação de rua.

A Política Nacional de Habitação, prevista na Lei 11.124/05, visa a equacionar as necessidades habitacionais do país, aos recursos existentes. Por isso, a destinação dos terrenos e edifícios vazios da União, dos Estados e dos Municípios deveria formar o estoque para a "[...] produção de moradias de interesse social e equipamentos públicos, combatendo a privatização dos imóveis públicos" (BrCidades, 2020: s.p.). Atendida a destinação desses edifícios situados nas áreas centrais para moradia de baixa renda, dotadas de infraestrutura, serviços e emprego, indicamos que as moradias sejam autogeridas pelos moradores. Dito isso, tendo em vista os dados expostos pelo CAU/ Folha, é intrínseca a uma coalizão de confronto a reivindicação da "[...] autogestão para a produção, reforma, melhorias habitacionais, urbanização e regularização fundiária de moradias e territórios populares, exigindo a implantação da Assistência Técnica à Habitação de Interesse Social (Lei 11.888/08)" (BrCidades, 2020: s.p.).

Como o foco principal desse artigo foi a mobilização do direito, propomos também, em acordo com a agenda nacional do BrCidades (2020), a garantia da "[...] existência de esferas de mediação de conflitos em áreas ocupadas por população pobre, evitando as remoções forçadas e combinando a observância de direitos humanos com a preservação ambiental e o cumprimento da função social da cidade" (BrCidades, 2020: s.p.), assim como a viabilização "[...] do acesso das camadas populares ao sistema de justiça, com vista à efetivação do seu direito à cidade, buscando aperfeiçoar os mecanismos que permitam que as necessidades sociais sejam consideradas de forma adequada nos processos judiciais" (BrCidades, 2020: s.p). 


\section{XII $\square$ SÃOPAULO15 17 LISBOA $25 \sim 26$ JUN 2020}

\section{Bibliografia}

A fiscalização da função social da propriedade nos municípios do Espírito Santo. (2017). NUDAM, DPES, Vitória, ES.

ALONSO, A. (2012). Repertório, segundo Charles Tilly: História de um Conceito. Revista Sociologia \& Antropologia, vol. 2, $n^{\circ}$ 3, p. 21-41, 2012.

COTELO; F. C. e MOITAY, R. (2008). Externalidades e formação de preços no mercado imobiliário urbano brasileiro: um estudo de caso. Revista Economia Aplicada (Ribeirão Preto), 2, 289-319.

Déficit Habitacional no Espírito Santo com base no CadÚnico (2016). IJSN. Vitória, ES. Boletim 01.

Diagnóstico para ações de revitalização do Centro de Vitória. (2002). PMV-SEDEC, HERKENHOFF, S. L. V. et al.. Vitória, ES.

DIANI, M. e BISON, I. (2010). Organizações, Coalizões e Movimentos. Revista Brasileira de Ciência Política, (Brasília), 3, 219-250.

Estatística e Informações: demografia e indicadores sociais. (2018). Déficit habitacional no Brasil: 2015. Diretoria de Estatística e Informações (DIREI), FJP, Belo Horizonte.

FIX, M. (2001). Parceiros da exclusão, duas histórias da construção de uma nova cidade em São Paulo: Faria Lima e Água Espraiada. São Paulo: Boitempo.

GONÇALVES, G L. (2020) Um porto no capitalismo global, desvendando a acumulação entrelaçada no Rio de Janeiro. Boitempo Editorial.

HARVEY, D. (2012). O Direito à Cidade. Lutas Sociais, São Paulo, n.29, p.73-89, jul./dez. 2012.

JASPER, J. (1997). The art of moral protest: culture, biography and creativity in social movements, The University of Chicago Press: Chicago and London, 1997, 514 p.

LEFÉBVRE, H. (2006). O direito à cidade. São Paulo: Centauro.

LOSEKANN, C. (2019). Performances coordenadas e experiências compartilhadas na mobilização do direito em conflitos ambientais: a contribuição do pragmatismo de John Dewey na análise de conflitos ambientais, in: Plural Revista de Ciências Sociais, Programa de Pós Graduação em Sociologia da USP, v. 26, n. 2, p. 174-199.

MCADAM, D.; TARROW, S.; TILLY, C.. (2001). Dynamics of contention. Cambridge University.

MCCANN, M. (2006). Law and Social Movements: Contemporary perspectives.Annu. Rev. Law Soc. Sci. 2:17-38.

MCCANN, M. (2010). Poder Judiciário e mobilização do direito: uma perspectiva dos usuários. In Anais do Seminário Nacional sobre Justiça Constitucional Revista Escola da Magistratura Regional Federal da $2^{\mathrm{a}}$ Região (Rio de Janeiro), 175-196.

MCCANN, M. (1994). Rights at work: pay equity reform and the politics of legal mobilization. Chicago/London: The University of Chicago Press, 358 p. 


\section{SÃOPAULO15 17 LISBOA $25 \sim 26$ JUN 2020}

PAULA, V. L. (2020). Ocupações e Defensoria Pública: Performances coordenadas de mobilização do direito na luta por moradia no Centro de Vitória. Dissertação de Mestrado do Programa de Pós-Graduação em Ciências Sociais - Universidade Federal do Espírito Santo. Vitória.

Planejamento Urbano Interativo do Centro (2006). Prefeitura Municipal de Vitória, Vitória, ES.

Plano de desenvolvimento urbano integrado Região Metropolitana da Grande Vitória. Diagnóstico integrado, v.2. (2018). IJSN. Vitória, ES.

Plano Diretor Urbano de Vitória. (2017). Lei no 290 de 2017. Prefeitura Municipal de Vitória, Conselho Municipal do Plano Diretor, Instituto Pólis. Vitória, ES.

SALES DE OLIVEIRA, N. (2017) Gentrificação e moradia social. Rio de Janeiro: Gramma.

SMITH, N. (2002) New Globalism, New Urbanism: Gentrification as Global Urban Strategy. Antipode 34:427450.

SMITH N. (2007). Gentrificação, a fronteira e a reestruturação do espaço urbano. Geousp - espaço e tempo (São Paulo), 21, 15-31.

TILLY, C. (2008). Contentious performances. Cambridge: Cambridge University Press, 235 p.

TILLY, C. (1977) From Mobilization to Revolution. Michigan, University of Michigan, 255 p.;

VAINER, C. (2011) Cidade de Exceção: reflexões a partir do Rio de Janeiro. Rio de Janeiro. v. 14 n. 1 ANAIS DO XIV ENANPUR.

\section{1. Fontes eletrônicas}

Agenda Nacional do Br Cidades. https://www.brcidades.org. (Consulta: 25/02/2020).

O maior diagnóstico sobre arquitetura e urbanismo já feito no Brasil. CAU Data Folha. https://www.caubr.gov.br/pesquisa2015/. (Consulta: 10/06/2019).

Cidade de São Paulo tem 206 ocupações onde moram 45 mil famílias. Portal G1. https://g1.globo.com/sp/sao-paulo/noticia/cidade-de-sao-paulo-tem-206-ocupacoes-onde-moram-45-milfamilias.ghtml (consulta: 03/02/2020). 